\title{
1 Recommendations for tissue homogenisation and extraction in DNA 2 metabarcoding of Malaise trap samples
}

3

4 Vera MA Zizka ${ }^{1 *}$, Matthias F Geiger ${ }^{1}$, Thomas Hörren², Ameli Kirse ${ }^{1}$, Niklas W Noll ${ }^{1}$, Livia Schäffler ${ }^{1}$,

5 Alice M Scherges ${ }^{1}$, Martin Sorg ${ }^{2}$

$7{ }^{1}$ Leibniz Institute for the Analysis of Biodiversity Change (LIB), Zoological Research Museum

8 Alexander Koenig (ZFMK), Centre for Biodiversity Monitoring and Conservation Science,

9 Adenauerallee 160, 53113 Bonn, Germany

$10{ }^{2}$ Entomological Society Krefeld (EVK), Marktstraße 159, 47798 Krefeld, Germany

11

12 Keywords: arthropod metabarcoding, biodiversity, monitoring, natura 2000

13

$14{ }^{*}$ Corresponding author:

15 Vera MA Zizka

16 Leibniz Institute for the Analysis of Biodiversity Change (LIB), Zoological Research Museum

17 Alexander Koenig, Adenauerallee 160, 53113 Bonn, Germany

18 Email: v.zizka@leibniz-zfmk.de

19 Phone: +49 (0) 2289122212

20

21

22 


\section{Abstract}

25 With increased application of DNA metabarcoding in fast and high-resolution biodiversity assessment, various laboratory protocols have been optimised in recent years and their further evaluation is subject of current research. Homogenisation of bulk samples and subsequent DNA extraction from destructed tissue is one way of starting the metabarcoding process. This essential step in the protocol can either be conducted from wet sample material (e.g. bulk insect samples) soaked in fixative or from completely dried individuals. While the latter method appears to produce more consistent results, it is time consuming and more prone to cross-contamination. We tested both homogenisation approaches with regard

33 to time efficiency and biodiversity assessment of complex arthropod bulk samples, in particular how the amount of processed tissue affects taxon recovery. Both approaches reveal similar taxa compositions and detect a similar total OTU diversity in a single extraction reaction. Increased amounts of tissue used in DNA extraction improved OTU diversity detection and recovered particularly specific low-biomass taxa, making this approach valuable for samples with high biomass and/or diversity. Due to less handling time and lower vulnerability for cross-contamination we recommend the processing of wet material when sample homogenisation is applied.

\section{Introduction}

43 For highly diverse groups as terrestrial arthropods and insects in particular, where 44 morphological identification is difficult, slow and expensive, metabarcoding provides an 45 efficient alternative (Bush et al., 2019; Evans et al., 2016; Morinière et al., 2019; van der 46 Heyde et al., 2020; Yu et al., 2012). In recent years, a variety of studies evaluated and 47 discussed promising sampling strategies (Gleason et al., 2020; Marquina et al., 2019; 48 Pereira-da-Conceicoa et al., 2020; Steinke et al., 2020), laboratory procedures (Elbrecht et 49 al., 2019; Majaneva et al., 2018; Piñol et al., 2019; Zizka et al., 2019), bioinformatic analyses 50 (Boyer et al., 2016; Frøslev et al., 2017; Porter and Hajibabaei, 2020; Turon et al., 2020) and 51 ways of integration into existing biodiversity monitoring matrices (Buchner et al., 2019;

52 Cordier et al., 2018; Mächler et al., 2020; Pawlowski et al., 2018). This resulted in a variety 53 of different DNA metabarcoding protocols, whereas standardisation is still lacking even 54 though it is a major prerequisite for inter-comparability and transferability of methods to 55 applied concepts (Bush et al., 2019; McGee et al., 2019; Pawlowski et al., 2018).

57 Aside from eDNA (environmental DNA) metabarcoding, where free extracellular DNA is 58 processed (e.g. from soil, water, faeces), DNA can be extracted from enclosed communities 
59 (cDNA), more precisely, the sample's fixative ethanol (Batovska et al., 2021; Hajibabaei et 60 al., 2012; Martins et al., 2019; Zizka et al., 2019) or propylene glycol (Martoni et al., 2021), 61 from added lysis buffer (Giebner et al., 2020; Ji et al., 2013; Kirse et al.,2021) or from

62 homogenised tissue of specimens (Hardulak et al., 2020; Mata et al., 2020; Zizka et al.,

63 2020). While the latter approach is currently considered most effective to assess biodiversity

64 pattern (Hardulak et al., 2020; Marquina et al., 2019; Persaud et al., 2021; Zenker et al., 65 2020; Zizka et al., 2019) it prevents subsequent morphological determinations (Nielsen et 66 al., 2019). Homogenisation and tissue-based DNA extraction can be conducted from wet 67 (Beentjes et al., 2019; Gibson et al., 2015; Porter et al., 2019) samples in ethanol or from 68 dried tissue after ethanol evaporation (Elbrecht et al., 2019; Hardulak et al., 2020; 69 Hausmann et al., 2020; Steinke et al., 2020). While powder homogenate of dried samples 70 usually appears finer than that of wet material, handling is more prone to cross 71 contamination and time consuming. Since most DNA extraction approaches tolerate only a 72 limited amount of tissue per reaction, only a subsample of complete material is usually 73 processed, ranging between 1-100 mg (Elbrecht et al., 2017; Hausmann et al., 2020; 74 Majaneva et al., 2018; Marquina et al., 2019; Mata et al., 2020). Higher tissue volume during 75 DNA extraction requires multiple reactions or more voluminous DNA extraction kits and is 76 increases effort and material costs. However, DNA extraction from the subsample tissue assumes perfect homogenisation and equal distribution within storage tubes, and it remains uncertain to what extent variations in tissue composition affects the assessment of species contained in bulk samples. Insight on that question is essential to decide on how to optimise diversity detection and is thus a prerequisite for successful and reliable application of tissuebased DNA metabarcoding. While Buchner et al. 2021 analyse the overlap in detected taxa between subsamples only for wet homogenisation of Malaise traps, other studies cover aquatic samples or other trapping types with lower biomass and diversity (Beentjes et al., 2019; Elbrecht et al., 2017; Mata et al., 2020). In addition, if several subsamples are applied, taxa detection is not compared amongst them or further methodological investigations are applied (e.g. comparison of different extraction methods (Majaneva et al., 2018). The overlap between subsamples of homogenised tissue or increases in taxon recovery by use of larger quantities of homogenised tissue in Malaise trap metabarcoding has never been tested systematically but bears important information for high resolution metabarcoding of terrestrial insect biodiversity.

Here we use five time-interval Malaise trap samples collected in a protected area in

94 Germany and investigate the effect of homogenisation strategy and tissue subsampling on 
recommendations for tissue-based DNA metabarcoding protocols esp. for Malaise trap

97 samples, which ensure time and money efficiency, best quality of biodiversity assessment

98 and also improved standardisation of DNA metabarcoding for biodiversity monitoring

99 programs.

\section{Material and Methods}

103 Sampling

104 Samples were collected in the Nature reserve 'Latumer Bruch' near Krefeld in Western

105 Germany. All samples originate from one Malaise trap (51.326701N, 6.632973E). Detailed

106 information about samples taken between May and July are given in Table 1.

108 Tab. 1: Malaise trap samples analysed: duration: time collection bottle was installed on the Malaise 109 trap, wet biomass: complete wet biomass ( $g$ ) and biomass per day ( $g /$ day) over sampling interval

\begin{tabular}{|l|l|l|l|}
\hline ID & duration & wet biomass $(\mathrm{g})$ & wet biomass $(\mathrm{g} /$ day $)$ \\
\hline T 1 & $12.05-18.05 .19$ & 14.1 & 2.4 \\
\hline T 2 & $29.05-08.06 .19$ & 65.9 & 6.7 \\
\hline T 3 & $28.06-07.07 .19$ & 71.7 & 8 \\
\hline T 4 & $07.07-18.07 .19$ & 40 & 3.6 \\
\hline T 5 & $18.07-28.07 .19$ & 70.1 & 7 \\
\hline
\end{tabular}

111 Malaise trap sampling was conducted in a standardised manner (for details see Ssymank et

112 al., 2018). Samples were collected in 96\% denatured ethanol (1\% MEK). After collection,

113 ethanol was replaced with new $96 \%$ undenatured ethanol and stored at $-20^{\circ} \mathrm{C}$ for further 114 processing. 


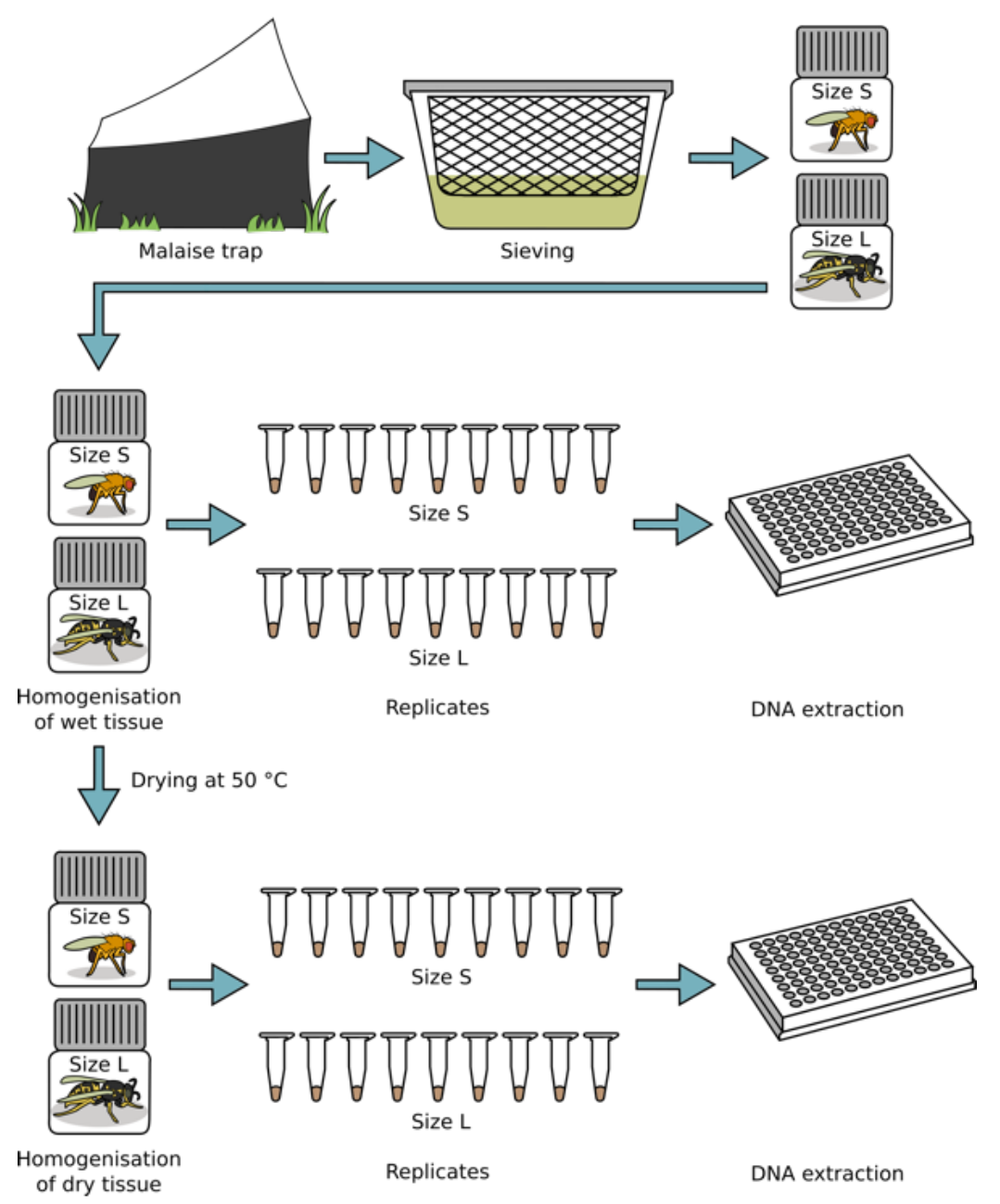

117 Figure 1: Experimental setup. Malaise trap samples were sieved in ethanol and separated into size 118 fraction Large $(>4 \mathrm{~mm})$ and Small $(<4 \mathrm{~mm})$. Wet tissue was homogenised and nine subsamples per size fraction with $\sim 20 \mathrm{mg}$ each were transferred to $1.5 \mu \mathrm{l}$ Eppendorf tubes for separate DNA extraction. Homogenised tissue was dried and again homogenised in dry conditions. Again, nine subsamples per size fraction with $\sim 20 \mathrm{mg}$ each were transferred to $1.5 \mu \mathrm{l}$ Eppendorf tubes. Subsequent DNA workflow was conducted as described in Material and Methods.

Laboratory work

125 Supernatant ethanol was removed and each sample was separated into two size classes by

126 sieving of wet specimen through a $4 \mathrm{~mm} \times 4 \mathrm{~mm}$ mesh with a wire diameter of $0.5 \mathrm{~mm}$ 127 (untreated stainless steel). In the following, the size fractions will be referred to as either $S$ 128 (small, $<4 \mathrm{~mm}$ ) or L (large, > $4 \mathrm{~mm}$ ). Depending on sample volume, individuals of both size 129 classes were transferred to $30 \mathrm{ml}$ tubes (Nalgene, wide-mouth bottle, polypropylene) or to 50 $130 \mathrm{ml}$ Falcon tubes, and approximately $20 \mathrm{~g}$ of grinding balls $(5 \mathrm{~mm}$ diameter, stainless steel, 131 Retsch $\mathrm{GmbH}$ ) were added to each sample. Homogenisation of wet samples was conducted 132 with a mixer mill MM 400 (Retsch $\mathrm{GmbH}$ ) at a frequency of $30 \mathrm{~s}^{-1}$ for five minutes. Nine 
133 subsamples per sample and size class were transferred to $1.5 \mathrm{ml}$ Eppendorf tubes, 134 centrifuged for 1 minute at 10,000 rpm (Heraeus Fresco 21 Centrifuge, Thermo Scientific) 135 and dried overnight in a shaking incubator (ILS6, VWR) at $50{ }^{\circ} \mathrm{C}$ (90 samples in total, 5 136 samples $\times 2$ treatments $\times 9$ subsamples). Subsamples were weighed (20 $\mathrm{mg} \pm 6 \mathrm{mg}$ ) on a 137 fine scale balance (Entris, Sartorius). Together with 6 negative controls (200 $\mu$ lysis buffer, 138 no sample added) and DNA was extracted with the DNeasy 96 Blood and Tissue Kit 139 (Quiagen, Hilden, Germany) following manufacturer instructions. Remaining sample tissue 140 (in $30 \mathrm{ml}$ tubes, not transferred to 1.5 Eppendorf tubes) was centrifuged for 1 minute at 4700 141 rpm (MegaStar 1.6, VWR Collection) and the supernatant discarded afterwards. Remaining 142 tissue was left to dry in a shaking incubator at $50{ }^{\circ} \mathrm{C}$ for up to 3 days until complete ethanol 143 evaporation. Dried tissue of samples containing less than $30 \mathrm{ml}$ was again homogenised at a

144 frequency of $30 \mathrm{~s} / \mathrm{sec}$ for 5 minutes with the Retsch mixer mill (MM400). Samples consisting 145 of more than $30 \mathrm{ml}$ source material were homogenised for 3 minutes with a Turax mixer mill 146 (Tube Mill 100 Control) at 25,000 rpm because dried material was clustered to a hard unit 147 and could not be destructed with the former mill. Nine subsamples per sample were transferred to 1.5 Eppendorf tubes and weighed $(23 \mathrm{mg} \pm 5 \mathrm{mg}$ ). To ensure processing of identical samples during this experiment, samples already homogenised under wet condition were dried and homogenised again under dry condition. Obviously, this includes an additional homogenisation step for those samples, which likely influences fineness of material. This will be picked up in the discussion. For simplicity, the former approach will hereinafter will be referred to as wet homogenisation, while the latter approach (wet with additional dry homogenisation) will be referred to as dry homogenisation. Together with 6 negative controls DNA was extracted with the DNeasy 96 Blood and Tissue Kit (Quiagen, Hilden, Germany) following manufacturer instructions for both plates. Extraction success and DNA quality was checked on a $1 \%$ agarose gel.

A two-step PCR protocol was applied using standard Illumina Nextera primers for dual indexing of samples. The first PCR was performed with the PCR Multiplex Plus Kit (Qiagen, Hilden, Germany) using $12.5 \mu \mathrm{l}$ master mix, $1 \mu \mathrm{l}$ of DNA template, $0.2 \mu \mathrm{M}$ of the fwhF2 forward (Vamos et al., 2017) and Fol_degen_rev reverse (Yu et al., 2012) primers respectively. The primer pair targets a $313 \mathrm{bp}$ long stretch of the COI DNA barcode region and was positively evaluated in a comparison on Malaise trap samples (Elbrecht et al.,

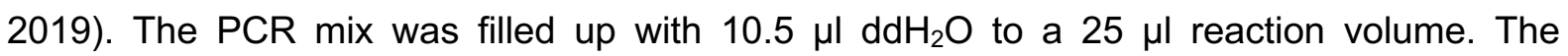
following PCR program was applied: initial denaturation at $95{ }^{\circ} \mathrm{C}$ for $5 \mathrm{~min} ; 25$ cycles of: $30 \mathrm{~s}$ 167 at $95{ }^{\circ} \mathrm{C}, 30 \mathrm{~s}$ at $50{ }^{\circ} \mathrm{C}$ and $50 \mathrm{~s}$ at $72{ }^{\circ} \mathrm{C}$; final extension of $5 \mathrm{~min}$ at $72{ }^{\circ} \mathrm{C}$. First step PCR 168 (PCR 1) product was used for the second PCR (PCR 2), also conducted with the PCR 169 Multiplex Plus Kit (Qiagen, Hilden, Germany). Reaction included $1 \mu$ I DNA template from 
170 PCR 1, $0.2 \mu \mathrm{M}$ of each tagging primer (Nextera, Illumina, San Diego, USA) and $12.5 \mu \mathrm{l}$

171 master mix filled up with $10.5 \mu \mathrm{H}_{2} \mathrm{O}$. Primers included a nucleotide overhang as a binding

172 site for primers in PCR 2, which was run with the same program as PCR 1 but with only 15

173 cycles. PCR success was evaluated on a $1 \%$ agarose gel before PCR products were

174 normalised using a SequalPrep Normalisation plate (Thermo Fisher Scientific, MA, USA)

175 following the manufacturer's instructions with an end concentration of $25 \mathrm{ng}$ per sample (100

$176 \mu \mathrm{l}$ ). Of each sample $10 \mu \mathrm{l}$ was pooled together and a left sided size selection was applied

177 twice on the sample pool to remove primer residuals (ration 0.76x, SPRIselect Beckman

178 Coulter). Library concentration was measured with a Quantus fluorometer (Promega,

179 Madison, USA) and on a fragment analyser (Agilent Technologies, Santa Clara, CA, USA)

180 and the pool was sent for sequencing on two Miseq runs ( $2 \times 300 \mathrm{bp})$ to Macrogen Europe

181 B.V., Netherlands.

182

183 Data analysis

184 The quality of sequences delivered by Macrogen was determined through the program

185 Fastqc (Andrews et al., 2012). Subsequent data processing was conducted for all samples

186 as implemented in JAMP v0.67 (https://github.com/VascoElbrecht/JAMP) using standard

187 settings. Paired-end reads were merged (Edgar and Flyvbjerg, 2015) (module Merge_PE)

188 with vsearch v2.15.0 (Rognes et al., 2016). Cutadapt 3.4 (Martin, 2017) was used to remove

189 primers and to discard sequences of unexpected length so that only reads with a length of

190303 - 323 bp were used for further analyses. The module Max_ee was used to discard all

191 reads with an expected error $>0.5$ (Edgar and Flyvbjerg, 2015). Sequences were

192 dereplicated, singletons were removed and sequences with $\geq 97 \%$ similarity were clustered

193 into Operational Taxonomic Units (OTUs) using uparse (Cluster_otus) (Edgar, 2013). OTUs

194 with a minimal read abundance of $0.003 \%$ per sample were retained for further analysis and

195 the program LULU was used for further qualitative filtering (Frøslev et al., 2017). Taxonomic

196 assignment of molecular units was conducted by comparison with an Arthropoda reference

197 database. The database was created by taxalogue (https://github.com/nwnoll/taxalogue

198 commit: 62ce71819af40a6e605e9142f0ccd69318477596) with sequences from BOLD

199 (https://www.boldsystems.org), NCBI GenBank (https://www.ncbi.nlm.nih.gov/genbank/) and

200 GBOL (https://bolgermany.de/gbol1/ergebnisse/results). Taxon names were normalised

201 according to the NCBI Taxonomy (https://www.ncbi.nlm.nih.gov/taxonomy). Only those

202 OTUs were kept that had at least $85 \%$ similarity with a sequence in a reference database

203 (using vsearch version 2.14.1 (Rognes et al., 2016) with -usearch_global command (Edgar,

204 2010) and the following parameters: -id 0.85, -dbmask none, -qmask none, -maxhits 1000,

205 blast6out and-maxaccepts 0 ). Custom scripts were used to extract the best hits and assign 


\section{Results}

214 On the two Miseq runs 13.3 and 14.7 million reads in forward and reverse direction were

each OTU a taxonomic name. For analysis of significant differences in OTU numbers between homogenisation methods and size fractions, a Kruskal-Wallis test was performed as integrated in the R package "dplyr" (Wickham et al., 2021). Dissimilarity indices were calculated with the package "vegan" (Oksanen et al., 2019). For species accumulation curves and associated calculations of extrapolated values the package "iNEXT" (Hsieh et al., 2016) was used. Figures were constructed with the R package ggplot (Wickham, 2016). assigned to the specified index combinations. Raw data are uploaded at GenBank (accession number: XX). After quality filtering, on average $114,394( \pm 20,365)$ reads were kept per sample. For both homogenisation approaches combined and all subsamples, in total 1,529 OTUs were clustered with the following order-level assignments: Coleoptera 158 (10.3\%), Diptera 372 (24.3\%), Hemiptera 134 (8.8\%), Hymenoptera 689 (45.1\%), Lepidoptera $52(3.4 \%)$, other orders $99(6.4 \%)$, no assignment to order level $25(1.6 \%)$. Of those, 1088 OTUs were assigned to genus or species level. Detailed information about OTU assignments and read distribution on order level are summarised in Table 1 and Table S1. While the highest number of OTUs was assigned on average to dipterans (L: $41.6 \%$, S: $37.5 \%$ ) and hymenopterans ( $\mathrm{L}: 38 \%, \mathrm{~S}: 32.3 \%$ ), the main proportion of reads was related to dipterans (L: $60.8 \%$, S: $77 \%$ ) and $<10 \%$ to representatives of Hymenoptera (Table 1). This was most pronounced for size fraction $S$, where on average only $4.7 \%$ of the reads were assigned to this highly diverse order.

Table 1: Average proportion of OTUs and reads assigned per time interval and through all samples to the orders Coleoptera, Diptera, Hemiptera, Hymenoptera, Lepidoptera, other arthropod orders and OTUs not assigned to order level (see table S1) for both homogenization approaches and all subsamples combined

\begin{tabular}{|c|c|c|c|c|}
\hline \multirow{2}{*}{ Order } & Size & OTU number [\%] & Read number [\%] & $\begin{array}{c}\text { Total OTU } \\
\text { number }\end{array}$ \\
\hline \multirow{2}{*}{ Coleoptera } & $\mathrm{L}$ & $5.7 \pm 1.9$ & $6 \pm 4.9$ & \multirow{2}{*}{$158(10.3 \%)$} \\
\cline { 2 - 4 } & $\mathrm{S}$ & $11.1 \pm 1$ & $5.5 \pm 2.8$ & \\
\hline \multirow{2}{*}{ Diptera } & $\mathrm{L}$ & $\mathbf{4 1 . 6 \pm 9 . 8}$ & $\mathbf{6 0 . 8} \pm 13.3$ & \multirow{2}{*}{$\mathbf{3} 372(\mathbf{2 4 . 4 \% )}$} \\
\cline { 2 - 4 } & $\mathrm{S}$ & $\mathbf{3 7 . 5} \pm \mathbf{8 . 8}$ & $\mathbf{7 7 \pm 1 1 . 9}$ & \\
\hline \multirow{2}{*}{ Hemiptera } & $\mathrm{L}$ & $3 \pm 0.8$ & $0.4 \pm 0.3$ & \multirow{2}{*}{$134(8.8 \%)$} \\
\cline { 2 - 4 } & $\mathrm{S}$ & $11.2 \pm 2.3$ & $10.1 \pm 10.7$ & \\
\hline
\end{tabular}




\begin{tabular}{|c|c|c|c|c|}
\hline \multirow{2}{*}{ Hymenoptera } & $\mathrm{L}$ & $\mathbf{3 8} \pm \mathbf{5 . 2}$ & $\mathbf{1 8 . 7 \pm 7 . 9}$ & \multirow{2}{*}{$689(\mathbf{4 5 . 1 \% )}$} \\
\cline { 2 - 4 } & $\mathrm{S}$ & $\mathbf{3 2 . 3} \pm \mathbf{7 . 5}$ & $\mathbf{4 . 7} \pm \mathbf{2 . 5}$ & \\
\hline \multirow{2}{*}{ Lepidoptera } & $\mathrm{L}$ & $7.6 \pm 3.2$ & $13.8 \pm 5.4$ & \multirow{2}{*}{$52(3.4 \%)$} \\
\cline { 2 - 4 } & $\mathrm{S}$ & $2.9 \pm 1.3$ & $1.8 \pm 1$ & \\
\hline \multirow{2}{*}{ Other arthropods } & $\mathrm{L}$ & $2.8 \pm 0.8$ & $0.3 \pm 0.2$ & \multirow{2}{*}{$98(6.4 \%)$} \\
\cline { 2 - 4 } & $\mathrm{S}$ & $3.6 \pm 0.6$ & $0.2 \pm 0.1$ & \multirow{2}{*}{$25(1.64 \%)$} \\
\hline & $\mathrm{L}$ & $1.2 \pm 0.4$ & $0.1 \pm 0.2$ & \\
\cline { 2 - 4 } & $\mathrm{S}$ & $1.3 \pm 0.3$ & $0.7 \pm 0.5$ & \\
\hline
\end{tabular}

235 While different emptying dates and the different size classes per sample showed distinct 236 community compositions (Fig. 2, p < 0.002), the condition during homogenisation (only wet 237 or wet and additional dry homogenisation) had no effect on sample ordination in NMDS 238 analysis ( $p=0.997$, Fig. 2). However, average Jaccard dissimilarity between subsamples 239 homogenised in wet and additional dry condition $(0.179 \pm 0.06)$ was lower $(p<0.001)$ than 240 dissimilarities between subsamples homogenised in only wet condition $(0.207 \pm 0.081)$ and 241 when subsamples of one emptying date and size fraction were compared amongst 242 homogenisation approaches $(0.206 \pm 0.089, p<0.001)$. Bray-Curtis dissimilarity was on 243 average lower within wet and dry $(0.11 \pm 0.07)$ compared to only wet $(0.11 \pm 0.09)$ 244 homogenised subsamples than comparing subsamples between methods $(0.13 \pm 0.08, p<$ 245 0.01).

246

A) Jaccard dissimilarity (stress $=0.08$ )

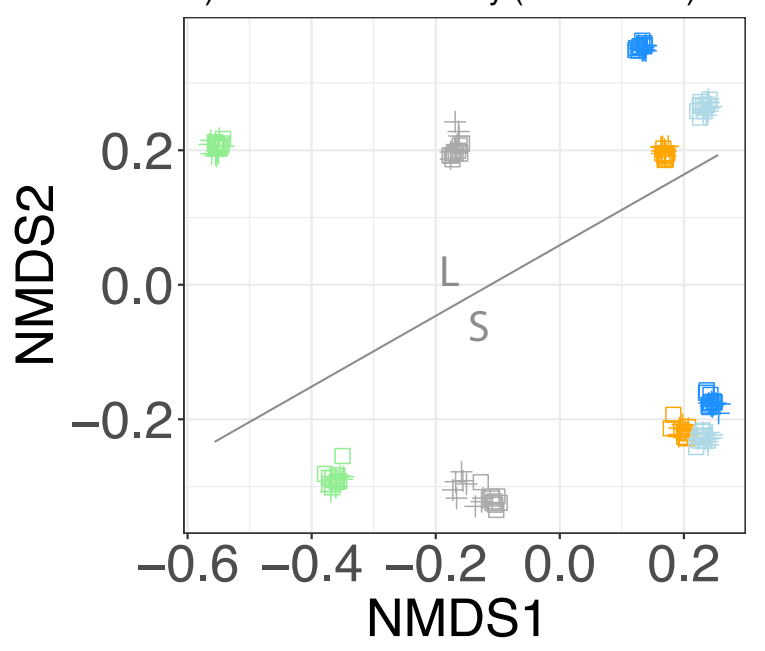

B) Bray-Curtis dissimilarity (stress $=0.07$ )

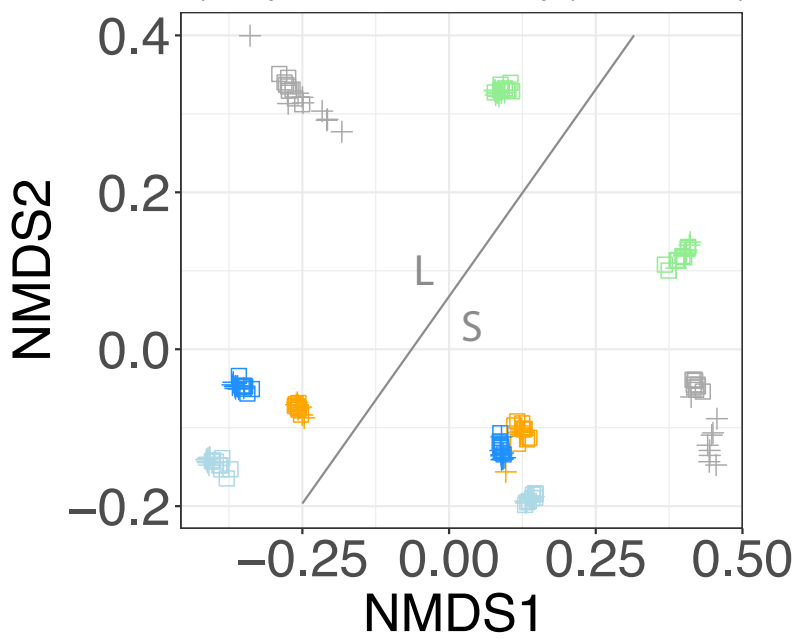


Figure 2: Non-metric multidimensional scaling based on A) Jaccard (presence/absence data) and B) Bray-Curtis (abundance data - regarding read numbers) dissimilarity matrices. Samples include the nine subsamples per emptying date (colour coding), size fraction ( $S$ and L, marked in figure) and condition during homogenisation (shape coding).

For samples processed under wet condition, on average $60.7 \% \pm 8.5$ of calculated total diversity could be detected in size fraction $S$ and $75.8 \% \pm 7.9$ in size fraction $L$ when only one subsample was processed in extraction ( $20 \mathrm{mg}$ of tissue, Fig. 3). With nine extraction subsamples $(9 \mathrm{x} \sim 20 \mathrm{mg}) 88.4 \% \pm 3.2$ and $92.4 \% \pm 4.2$ of calculated total richness were detected in fraction $S$ and $L$ respectively, while $95 \%$ of calculated species richness was assessed with $12 \pm 5.4$ and $17 \pm 3.4$ subsamples. For samples homogenised in wet and additional dry condition, a single extraction $(\sim 20 \mathrm{mg})$ of size class $\mathrm{S}$ revealed $64 \% \pm 2.3$ of calculated species richness, while $79 \% \pm 3.8$ could be detected in $20 \mathrm{mg}$ of size class $\mathrm{L}$ (Fig. 3). On average $88.9 \% \pm 1.6$ of total diversity was assessed with the nine applied subsamples for size fraction $S$ and $93.1 \% \pm 3.8$ for size fraction $L$, while $95 \%$ of total was calculated with $16 \pm 2.1(\mathrm{~S}, 320 \mathrm{mg})$ and $13 \pm 7.1(\mathrm{~L}, 260 \mathrm{mg})$ subsamples ( $320 \mathrm{mg}$ and $\sim 260$ mg, Fig. 3).

Detailed analysis of Hymenoptera in only wet homogenised tissue revealed on average $47.2 \% \pm 13.3$ of extrapolated total species richness in size fraction $S$ and $80.4 \% \pm 10.4$ in size fraction $L$ when a single subsample was processed (Fig.3). Increased to nine subsamples, $81.4 \% \pm 7.6(\mathrm{~S})$ and $96.2 \% \pm 4.7(\mathrm{~L})$ of calculated total diversity were detected. Extrapolations revealed, that $95 \%$ of total calculated diversity was achieved by processing $22 \pm 5.2(\mathrm{~S}, \sim 440 \mathrm{mg})$ and $7.4 \pm 6(\mathrm{~L}, \sim 140 \mathrm{mg})$ replicates. For wet and additional dry homogenisation, one extraction subsample revealed $54 \% \pm 2.7(\mathrm{~S})$ and $82.4 \% \pm 9.6(\mathrm{~L})$ of total species richness, while $86.2 \% \pm 3.1$ and $95.1 \% \pm 4.8$ could be assessed with nine extraction subsamples. Calculations revealed a detection of $95 \%$ from total hymenopteran species richness if $18 \pm 4(360 \mathrm{mg})$ and $9.8 \pm 8(200 \mathrm{mg})$ replicates were processed (Fig. 3).

For wet homogenisation, in detail analysis of dipteran representatives revealed $70.6 \% \pm 5.6$ of calculated diversity in size fraction $\mathrm{S}$ and $77 \% \pm 10.3$ in size fraction $\mathrm{L}$, when only a single extraction subsample was processed. Detected richness increased to $92.1 \% \pm 4.7$ and $91 \%$ \pm 5.6 when nine subsamples were processed (95\% were reached with $14.2 \pm 7.9$ and $5 \pm 1.9$ subsamples). With additional dry homogenisation processing of one tissue subsample revealed $70.6 \% \pm 2.7$ of extrapolated diversity for size fraction $S$ and $81.1 \pm 5.9$ for size

283 fraction L. With nine extraction subsamples, taxa detection increased to $91.2 \% \pm 3.4(\mathrm{~S})$ and

$28493.3 \% \pm 5.5(\mathrm{~L})$. Calculations revealed a detection of 95\% from total Diptera if $15.6 \pm 5.4$ 
bioRxiv preprint doi: https://doi.org/10.1101/2022.01.25.477667; this version posted January 26,2022 . The copyright holder for this preprint (which was not certified by peer review) is the author/funder, who has granted bioRxiv a license to display the preprint in perpetuity. It is made available under aCC-BY-ND 4.0 International license.

285 ( 320 mg) and $14.2 \pm 10.2(\sim 200 \mathrm{mg})$ replicates were processed. For detailed information about observed and calculated species richness see Figure 3.

A) Dry homogenisation all taxa
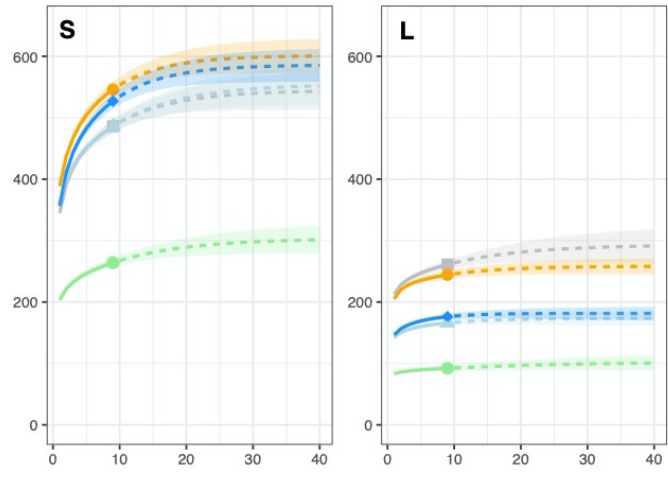

C) Dry homogenisation Diptera
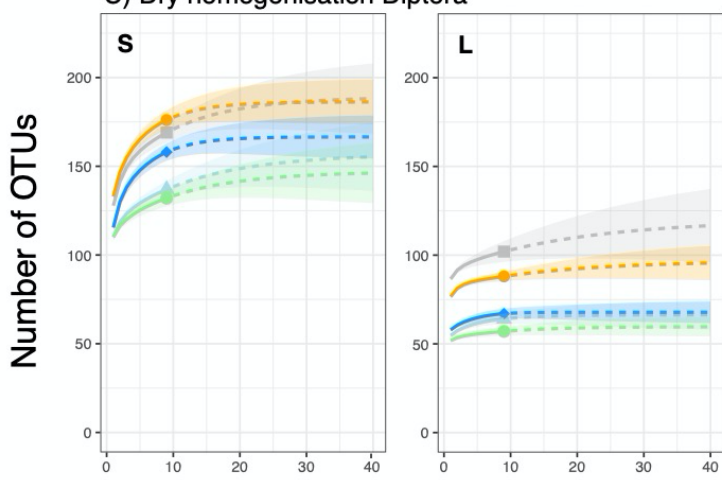

E) Dry homogenisation Hymenoptera
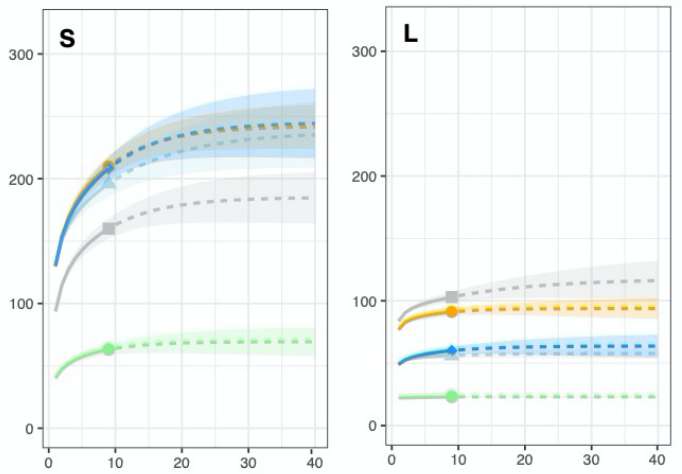

B) Wet homogenisation all taxa
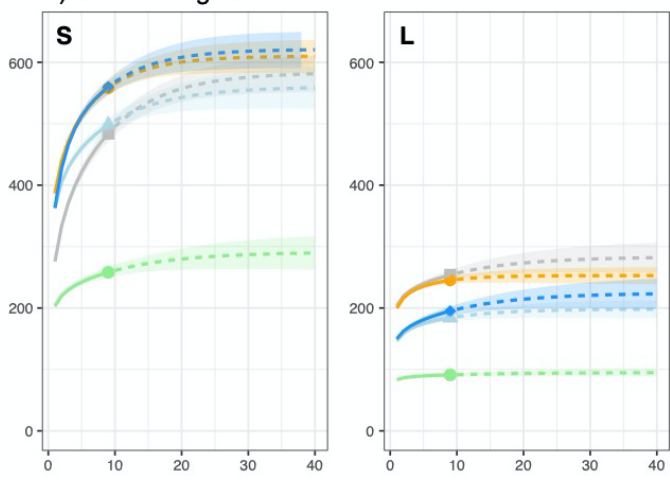

D) Wet homogenisation Diptera
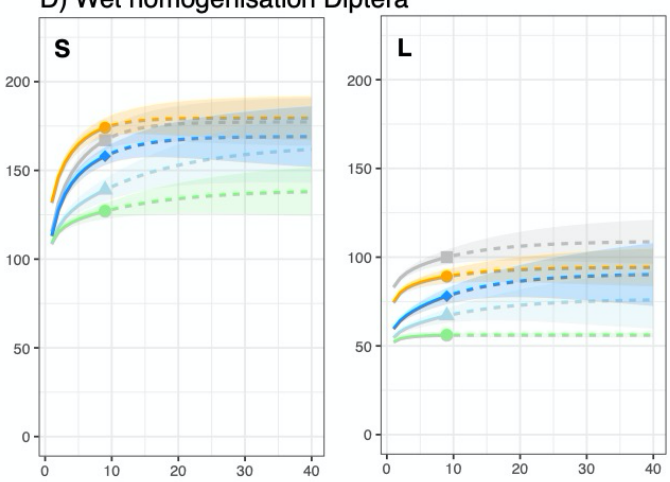

F) Wet homogenisation Hymenoptera
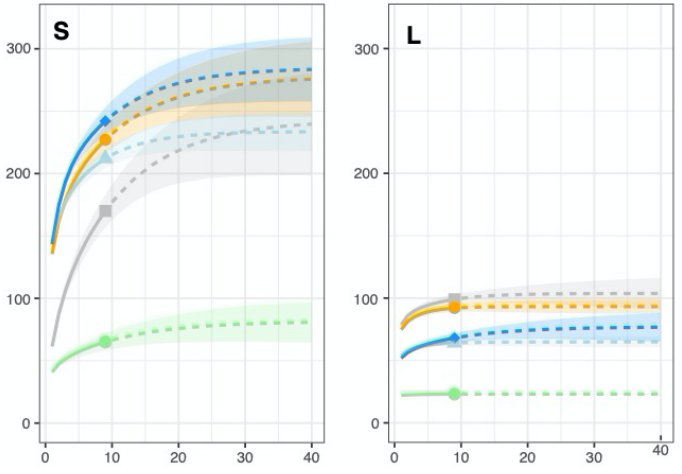

Number of tissue subsamples

May 18th June 8th July 7th July 18th July 28th

Figure 3: Species accumulation curves. Increased number of OTUs with increased amount of processed tissue in extraction is illustrated as well as extrapolation up to 40 subsamples. All taxa homogenized in A) dry and B) wet condition; Diptera recovered in samples homogenised in C) dry and D) wet condition; Hymenoptera detected in samples homogenised in E) dry and F) wet condition. Size fraction is marked in the upper left corner of each subfigure $(S=$ small, $L=$ large). 

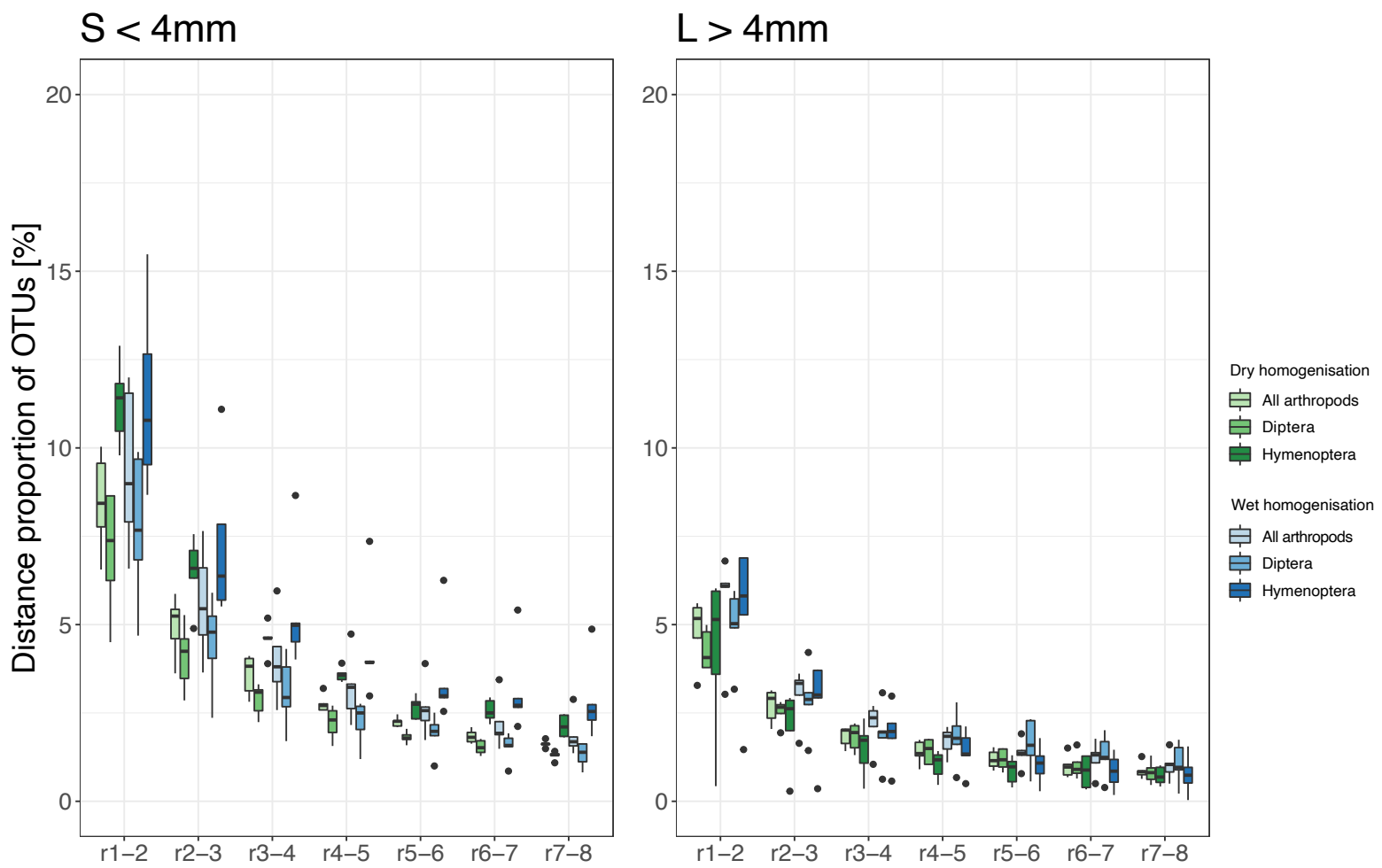

Figure 4: Proportion of molecular units (OTUs) detected with additional DNA extraction subsamples. A) for samples of size fraction $L(>4 \mathrm{~mm})$ and $B)$ for size fraction $S(<4 \mathrm{~mm})$. The $x$-axis describes differences between processed subsamples (e.g. r1-r2 difference in relative number of OTUs detected with one subsamples $(\sim 20 \mathrm{mg})$ compared to two subsamples ( 40 mg)).

\section{Discussion}

Homogenisation of bulk samples and subsequent DNA extraction from destructed tissue is widely applied when insect biodiversity is assessed through DNA metabarcoding (Beermann et al., 2021; Hardulak et al., 2020; Mata et al., 2020). It is up to now more efficient for bulk sample analysis than other extraction methods (Marquina et al., 2019; Persaud et al., 2021;

310 Zenker et al., 2020). Here we set out to test different homogenisation protocols and how

311 subsampling of homogenised tissue affects diversity estimates of highly diverse Malaise trap 312 samples.

314 Comparison of different homogenisation approaches

315 The average dissimilarity between reactions homogenised under dry conditions was lower 316 than dissimilarity between reactions processed under wet condition for presence/absence 317 analysis, which indicates a higher homogeneity of tissue samples processed under dry 318 condition. To ensure comparability and processing of identical sampling material (as stated 
319 in Material and Methods section line 150-156), the dry homogenisation approach was based 320 on material already destructed under wet condition. This additional step of $3 \mathrm{~min}$ 321 homogenisation most probably influenced refinement of samples and similarity of 322 subsamples. In addition, on average a lower tissue weight was processed subsequent to wet

323 homogenisation due to a weight decrease after drying (difference $3 \mathrm{mg}$ ). However, Jaccard's 324 dissimilarity indices of subsamples which were homogenised in wet condition was on 325 average $0.21 \pm 0.08$, mainly due to high inconsistencies between subsamples from June $8^{\text {th }}$ 326 with an average dissimilarity of $0.35 \pm 0.02$ compared to dissimilarities between subsamples 327 of the other collection dates $(0.18 \pm 0.06$; Fig. 2$)$. The homogenisation of dried samples 328 implements drying for approximately $48 \mathrm{~h}$ at temperatures around $50{ }^{\circ} \mathrm{C}$ to guarantee the 329 complete evaporation of ethanol from the sample. In addition, the fine powder resulting from 330 dry homogenisation is electrostatically charged and thus bears a high risk of cross 331 contamination between samples and general lab contamination, and further increases the 332 time for sample handling (Buchner et al., 2021; Elbrecht and Steinke, 2019). In comparison, 333 the homogenisation of wet samples soaked in ethanol circumvents the drying step and is 334 therefore more time efficient and suitable for large scale approaches as implemented in 335 several studies on aquatic samples (Hajibabaei et al., 2019; Majaneva et al., 2018; Pereira336 da-Conceicoa et al., 2020). In addition, the handling of homogenised tissue in ethanol is 337 simplified and reduces contamination risk (Elbrecht and Steinke, 2019). The minor 338 differences we observed between the two applied methods and the above-mentioned experimental setup allows to recommend homogenisation of wet material for tissue-based DNA metabarcoding Malaise trap samples as it reduces processing time and contamination risk. Additionally, results indicate, that an additional homogenisation step of dried material as e.g. through bead-grinding should be integrated after material has been subsampled to increase the fineness of material as also conducted in Buchner et al., 2021.

345 Amount of tissue needed for homogenisation

346 A high, but incomplete proportion of the total insect diversity was assessed when processing 347 a single tissue subsample in extraction, which opens up an additional perspective to previous studies highlighting wet homogenisation of samples (Buchner et al., 2021). This accounts for both tested variables, basis material for homogenisation (wet or dry) and size fractions (Fig. 3). For all samples at least $60 \%$ of calculated total arthropod diversity were detected with a single extraction from $\sim 20 \mathrm{mg}$ of tissue (Fig. $3 \mathrm{~A}+\mathrm{B}$ ), revealing strong alterations between size fractions time intervals and higher insect taxa. The processing of

353 additional subsamples only moderately increase diversity estimates for size fraction $L$ and 354 samples of both size fractions from samples collected in May. While those samples 355 constitute a comparatively low biodiversity, a strong increase was detected for remaining 
samples of the small size fractions and collected in summer. Results indicate that extraction should be conducted from more tissue for highly diverse samples, either through increasing number of extraction subsamples, as it was also recommended in (Elbrecht and Steinke, 2019) or a higher tissue volume per DNA extraction. Additional rare material for extraction however comes with higher expenses but can increases taxa detection by $25-30 \%$ as an average over all taxa. Referring to the 3000 BINs detected within a year-long Malaise trap collection through single-specimen barcoding in Geiger et al., 2016 this can result in 600-900 additional molecular units for year-long application of a malaise trap.

The most pronounced increase of OTUs with additional extraction subsamples was observed for representatives of the order Hymenoptera, which is almost twice as high as for Diptera (Fig. 3, Tab. 2). Representatives of these two orders are the main targets in many Malaise trapping studies (Ssymank et al., 2018). However, as also indicated with previous studies, dipterans are present in much higher individual numbers, constituting a higher proportion of biomass in Malaise trap catches in Germany, while diversity of both groups are considered to be similar (Geiger et al., 2016). An underrepresentation of specific insect families, especially constituting taxa of low-biomass (Elbrecht et al., 2021) has been reported from previous metabarcoding studies (Elbrecht and Steinke, 2019; Krehenwinkel et al., 2017; Yu et al., 2012). This accounts e.g. for highly diverse parasitoid hymenopterans, which depict important ecosystem functions. While insufficient primer binding efficiency is discussed as the main reason for this phenomenon, our results indicate, that the extraction from an insufficient amount of raw tissue material could also bias detected diversity pattern. It also assumes that taxon biomass in complex bulk samples is affecting detection probability if a limited amount of tissue is processed in extraction but can be increased through insertion of higher tissue amounts. Again, this accounts especially for highly diverse samples as indicated here through the small size fraction. We demonstrate, that the use of higher amount of tissue of approx. $180 \mathrm{mg}$ over nine subsamples increase the detection of low biomass taxa, even if general sequence coverage remains low ( $5 \%$ of reads assigned to Hymenoptera, Table 1). Additionally, the application of higher sequencing depth can increase taxa recovery and overlap between extraction subsamples. We here only tested a sequencing depth of on average 114,394 $\pm 20,365$ reads per sample (after quality filtering) and detailed analysis to understand the linkage between higher sequencing depth and replication strategy is out of the scope of the present study. Further investigation could reveal an increase in sequencing depth as the most effective way to optimise taxon recovery under financial constraints. 


\section{Conclusion}

393 We recommend homogenisation of wet material in tissue-based DNA metabarcoding of Malaise trap samples due to similar levels of taxon recovery from dry and wet tissue homogenisation combined with a lower time effort and contamination susceptibility of the latter approach. In both, dry and wet homogenisation, additional DNA extractions from more tissue results in a higher number of detected taxa, in particular those of low biomass. The amount of processed tissue and number of subsamples affects the resolution taxaspecifically. A decision on the more complete diversity detection associated with higher resources depends on the focused scientific goals of individual studies.

\section{Data Accessibility}

The raw sequence used in this study is available at NCBI SRA: XX

\section{Competing Interests}

The authors declare no competing interests

\section{Acknowledgements}

This work was supported by the Ministry for Environment, Agriculture, Conservation and

\section{References}

Andrews, S., Krueger, F., Segonds-Pichon, A., Biggins, L., Krueger, C., Wingett, S., 2012. FastQC. Babraham, UK.

Andújar, C., Creedy, T.J., Arribas, P., López, H., Salces-Castellano, A., Pérez-Delgado, A., Vogler, A.P., Emerson, B.C., 2020. Validated removal of nuclear pseudogenes and sequencing artefacts from mitochondrial metabarcode data. bioRxiv 2020.06.17.157347. https://doi.org/10.1101/2020.06.17.157347

Arribas, P., Andújar, C., Bidartondo, M.I., Bohmann, K., Coissac, É., Creer, S., deWaard, J.R., Elbrecht, V., Ficetola, G.F., Goberna, M., Kennedy, S., Krehenwinkel, H., Leese, F., Novotny, V., Ronquist, F., Yu, D.W., Zinger, L., Creedy, T.J., Meramveliotakis, E., Noguerales, V., Overcast, I., Morlon, H., Vogler, A.P., Papadopoulou, A., Emerson, B.C., 2021. Connecting high-throughput biodiversity inventories: Opportunities for a site-based genomic framework for global integration and synthesis. Mol. Ecol. 30, 1120-1135. https://doi.org/10.1111/mec.15797

Batovska, J., Lynch, S.E., Cogan, N.O.I., Brown, K., Darbro, J.M., Kho, E.A., Blacket, M.J., 2018. Effective mosquito and arbovirus surveillance using metabarcoding. Mol. Ecol. Resour. 18, 32-40. https://doi.org/10.1111/1755-0998.12682

Batovska, J., Piper, A., Valenzuela, 2021. Developing a Non-destructive Metabarcoding Protocol for Detection of Pest Insects in Bulk Trap Catches.

Beentjes, K.K., Speksnijder, A.G.C.L., Schilthuizen, M., Hoogeveen, M., Pastoor, R., van der Hoorn, B.B., 2019. Increased performance of DNA metabarcoding of 
macroinvertebrates by taxonomic sorting. PLOS ONE 14, e0226527. https://doi.org/10.1371/journal.pone.0226527

Boyer, F., Mercier, C., Bonin, A., Le Bras, Y., Taberlet, P., Coissac, E., 2016. obitools: a unix-inspired software package for DNA metabarcoding. Mol. Ecol. Resour. 16, 176182. https://doi.org/10.1111/1755-0998.12428

Buchner, D., Beermann, A.J., Laini, A., Rolauffs, P., Vitecek, S., Hering, D., Leese, F., 2019. Analysis of 13,312 benthic invertebrate samples from German streams reveals minor deviations in ecological status class between abundance and presence/absence data. PLOS ONE 14, e0226547. https://doi.org/10.1371/journal.pone.0226547

Buchner, D., Leese, F., 2020. BOLDigger - a Python package to identify and organise sequences with the Barcode of Life Data systems. Metabarcoding Metagenomics 4, e53535. https://doi.org/10.3897/mbmg.4.53535

Bush, A., Compson, Z.G., Monk, W.A., Porter, T.M., Steeves, R., Emilson, E., Gagne, N., Hajibabaei, M., Roy, M., Baird, D.J., 2019. Studying Ecosystems With DNA Metabarcoding: Lessons From Biomonitoring of Aquatic Macroinvertebrates. Front. Ecol. Evol. 7, 434. https://doi.org/10.3389/fevo.2019.00434

Bush, A., Monk, W.A., Compson, Z.G., Peters, D.L., Porter, T.M., Shokralla, S., Wright, M.T.G., Hajibabaei, M., Baird, D.J., 2020. DNA metabarcoding reveals metacommunity dynamics in a threatened boreal wetland wilderness. Proc. Natl. Acad. Sci. 117, 8539. https://doi.org/10.1073/pnas.1918741117

Cordier, T., Forster, D., Dufresne, Y., Martins, C.I.M., Stoeck, T., Pawlowski, J., 2018. Supervised machine learning outperforms taxonomy-based environmental DNA metabarcoding applied to biomonitoring. Mol. Ecol. Resour. 18, 1381-1391. https://doi.org/10.1111/1755-0998.12926

Elbrecht, V., Braukmann, T.W.A., Ivanova, N.V., Prosser, S.W.J., Hajibabaei, M., Wright, M., Zakharov, E.V., Hebert, P.D.N., Steinke, D., 2019. Validation of COI metabarcoding primers for terrestrial arthropods. PeerJ 7, e7745. https://doi.org/10.7717/peerj.7745

Elbrecht, V., Vamos, E.E., Meissner, K., Aroviita, J., Leese, F., 2017. Assessing strengths and weaknesses of DNA metabarcoding-based macroinvertebrate identification for routine stream monitoring. Methods Ecol. Evol. 8, 1265-1275. https://doi.org/10.1111/2041-210X.12789

Evans, D.M., Kitson, J.J.N., Lunt, D.H., Straw, N.A., Pocock, M.J.O., 2016. Merging DNA metabarcoding and ecological network analysis to understand and build resilient terrestrial ecosystems. Funct. Ecol. 30, 1904-1916. https://doi.org/10.1111/13652435.12659

Frøslev, T.G., Kjøller, R., Bruun, H.H., Ejrnæs, R., Brunbjerg, A.K., Pietroni, C., Hansen, A.J., 2017. Algorithm for post-clustering curation of DNA amplicon data yields reliable biodiversity estimates. Nat. Commun. 8, 1188. https://doi.org/10.1038/s41467-01701312-x

Giebner, H., Langen, K., Bourlat, S.J., Kukowka, S., Mayer, C., Astrin, J.J., Misof, B., Fonseca, V.G., 2020. Comparing diversity levels in environmental samples: DNA sequence capture and metabarcoding approaches using $18 \mathrm{~S}$ and COI genes. Mol. Ecol. Resour. 20, 1333-1345. https://doi.org/10.1111/1755-0998.13201

Geiger, M. F., Moriniere, J., Hausmann, A., Haszprunar, G., Wägele, W., Hebert, P. D., \& Rulik, B. (2016). Testing the Global Malaise Trap Program-How well does the current barcode reference library identify flying insects in Germany?. Biodiversity data journal, (4).

Gleason, J.E., Elbrecht, V., Braukmann, T.W.A., Hanner, R.H., Cottenie, K., 2020. Assessment of stream macroinvertebrate communities with eDNA is not congruent with tissue-based metabarcoding. Mol. Ecol. n/a. https://doi.org/10.1111/mec.15597

Hajibabaei, M., Spall, J.L., Shokralla, S., van Konynenburg, S., 2012. Assessing biodiversity of a freshwater benthic macroinvertebrate community through non-destructive environmental barcoding of DNA from preservative ethanol. BMC Ecol. 12, 28. https://doi.org/10.1186/1472-6785-12-28 
Hardulak, L.A., Moriniere, J., Hausmann, A., Hendrich, L., Schmidt, S., Doczkal, D., Müller, J., Hebert, P.D., Haszprunar, G., 2020. DNA metabarcoding for biodiversity monitoring in a national park: Screening for invasive and pest species. Mol. Ecol. Resour. 1-16. https://doi.org/10.1111/1755-0998.13212

Hausmann, A., Segerer, A.H., Greifenstein, T., Knubben, J., Morinière, J., Bozicevic, V., Doczkal, D., Günter, A., Ulrich, W., Habel, J.C., 2020. Toward a standardized quantitative and qualitative insect monitoring scheme. Ecol. Evol. 10, 4009-4020. https://doi.org/10.1002/ece3.6166

Ji, Y., Ashton, L., Pedley, S.M., Edwards, D.P., Tang, Y., Nakamura, A., Kitching, R., Dolman, P.M., Woodcock, P., Edwards, F.A., Larsen, T.H., Hsu, W.W., Benedick, S., Hamer, K.C., Wilcove, D.S., Bruce, C., Wang, X., Levi, T., Lott, M., Emerson, B.C., Yu, D.W., 2013. Reliable, verifiable and efficient monitoring of biodiversity via metabarcoding. Ecol. Lett. 16, 1245-1257. https://doi.org/10.1111/ele.12162

Kirse, A., Bourlat, S.J., Lange, K., Fonseca, V.G., n.d. Arthropod diversity assessment from the ground up: Seasonal overlap between soil and Malaise traps. Rev.

Mächler, E., Walser, J.-C., Altermatt, F., 2020. Decision-making and best practices for taxonomy-free environmental DNA metabarcoding in biomonitoring using Hill numbers. Mol. Ecol. n/a. https://doi.org/10.1111/mec.15725

Majaneva, M., Diserud, O.H., Eagle, S.H.C., Hajibabaei, M., Ekrem, T., 2018. Choice of DNA extraction method affects DNA metabarcoding of unsorted invertebrate bulk samples. Metabarcoding Metagenomics 2, e26664. https://doi.org/10.3897/mbmg.2.26664

Marquina, D., Esparza-Salas, R., Roslin, T., Ronquist, F., 2019. Establishing arthropod community composition using metabarcoding: Surprising inconsistencies between soil samples and preservative ethanol and homogenate from Malaise trap catches. Mol. Ecol. Resour. 19, 1516-1530. https://doi.org/10.1111/1755-0998.13071

Martin, M., 2011. Cutadapt removes adapter sequences from high-throughput sequencing reads. EMBnetjournal Vol 17 No 1 Gener. Seq. Data Anal. https://doi.org/10.14806/ej.17.1.200

Martins, F.M.S., Galhardo, M., Filipe, A.F., Teixeira, A., Pinheiro, P., Paupério, J., Alves, P.C., Beja, P., 2019. Have the cake and eat it: Optimizing nondestructive DNA metabarcoding of macroinvertebrate samples for freshwater biomonitoring. Mol. Ecol. Resour. 19, 863-876. https://doi.org/10.1111/1755-0998.13012

Martoni, F., Nogarotto, E., Piper, A.M., Mann, R., Valenzuela, I., Eow, L., Rako, L., Rodoni, B.C., Blacket, M.J., 2021. Propylene Glycol and Non-Destructive DNA Extractions Enable Preservation and Isolation of Insect and Hosted Bacterial DNA. Agriculture 11. https://doi.org/10.3390/agriculture11010077

Mata, V.A., Ferreira, S., Campos, R.M., da Silva, L.P., Veríssimo, J., Corley, M.F.V., Beja, P., 2020. Efficient assessment of nocturnal flying insect communities by combining automatic light traps and DNA metabarcoding. Environ. DNA n/a. https://doi.org/10.1002/edn3.125

McGee, K.M., Robinson, C.V., Hajibabaei, M., 2019. Gaps in DNA-Based Biomonitoring Across the Globe. Front. Ecol. Evol. 7, 337. https://doi.org/10.3389/fevo.2019.00337

Morinière, J., Balke, M., Doczkal, D., Geiger, M.F., Hardulak, L.A., Haszprunar, G., Hausmann, A., Hendrich, L., Regalado, L., Rulik, B., Schmidt, S., Wägele, J.-W., Hebert, P.D.N., 2019. A DNA barcode library for 5,200 German flies and midges (Insecta: Diptera) and its implications for metabarcoding-based biomonitoring. Mol. Ecol. Resour. 19, 900-928. https://doi.org/10.1111/1755-0998.13022

Oksanen, J., Blanchet, F.G., Friendl, M., Kindt, R., Legendre, P., McGlinn, D., Minchin, P.R., O'Hara, R.B., Simpson, G.L., Solymos, P., Stevens, M.H.H., Szoecs, E., Wagner, H., 2019. Vegan: community ecology package.

Pawlowski, J., Kelly-Quinn, M., Altermatt, F., Apothéloz-Perret-Gentil, L., Beja, P., Boggero, A., Borja, A., Bouchez, A., Cordier, T., Domaizon, I., Feio, M.J., Filipe, A.F., Fornaroli, R., Graf, W., Herder, J., van der Hoorn, B., Iwan Jones, J., SagovaMareckova, M., Moritz, C., Barquín, J., Piggott, J.J., Pinna, M., Rimet, F., Rinkevich, B., Sousa-Santos, C., Specchia, V., Trobajo, R., Vasselon, V., Vitecek, S., 
Zimmerman, J., Weigand, A., Leese, F., Kahlert, M., 2018. The future of biotic indices in the ecogenomic era: Integrating (e)DNA metabarcoding in biological assessment of aquatic ecosystems. Sci. Total Environ. 637-638, 1295-1310. https://doi.org/10.1016/j.scitotenv.2018.05.002

Pedro, P.M., Rodrigues de Sá, I.L., Rojas, M.V.R., Amorim, J.A., Ribeiro Galardo, A.K., Santos Neto, N.F., Furtado, N.V.R., Pires de Carvalho, D., Nabas Ribeiro, K.A., de Paiva, M., Pepe Razzolini, M.T., Sallum, M.A.M., 2020. Efficient Monitoring of Adult and Immature Mosquitoes Through Metabarcoding of Bulk Samples: A Case Study for Non-Model Culicids With Unique Ecologies. J. Med. Entomol. https://doi.org/10.1093/jme/tjaa267

Pereira-da-Conceicoa, L., Elbrecht, V., Hall, A., Briscoe, A., Barber-James, H., Price, B., 2020. Metabarcoding unsorted kick-samples facilitates macroinvertebrate-based biomonitoring with increased taxonomic resolution, while outperforming environmental DNA. Environ. DNA n/a. https://doi.org/10.1002/edn3.116

Persaud, S.F., Cottenie, K., Gleason, J.E., 2021. Ethanol eDNA Reveals Unique Community Composition of Aquatic Macroinvertebrates Compared to Bulk Tissue Metabarcoding in a Biomonitoring Sampling Scheme. Diversity 13, 34.

Piñol, J., Senar, M.A., Symondson, W.O.C., 2019. The choice of universal primers and the characteristics of the species mixture determine when DNA metabarcoding can be quantitative. Mol. Ecol. 28, 407-419. https://doi.org/10.1111/mec.14776

Porter, T.M., Hajibabaei, M., 2020. Putting COI Metabarcoding in Context: The Utility of Exact Sequence Variants (ESVs) in Biodiversity Analysis. Front. Ecol. Evol. 8, 248. https://doi.org/10.3389/fevo.2020.00248

Porter, T.M., Morris, D.M., Basiliko, N., Hajibabaei, M., Doucet, D., Bowman, S., Emilson, E.J.S., Emilson, C.E., Chartrand, D., Wainio-Keizer, K., Séguin, A., Venier, L., 2019. Variations in terrestrial arthropod DNA metabarcoding methods recovers robust beta diversity but variable richness and site indicators. Sci. Rep. 9, 18218. https://doi.org/10.1038/s41598-019-54532-0

R Core Team, 2017. R: A language and environment for statistical computing.

Rognes, T., Flouri, T., Nichols, B., Quince, C., Mahé, F., 2016. VSEARCH: a versatile open source tool for metagenomics. PeerJ 4, e2584. https://doi.org/10.7717/peerj.2584

Ssymank, A., Sorg, M., Doczkal, D., Rulik, B., Merkel-Wallner, G., Vischer-Leopold, M., 2018. Praktische Hinweise und Empfehlungen zur Anwendung von Malaisefallen für Insekten in der Biodiversitätserfassung und im Monitoring. Ser. Nat. 1, 1-12.

Steinke, D., Braukmann, T., Manerus, L., Woodhouse, A., Elbrecht, V., 2020. Effects of Malaise trap spacing on species richness and composition of terrestrial arthropod bulk samples. bioRxiv 2020.09.30.321430. https://doi.org/10.1101/2020.09.30.321430

Turon, X., Antich, A., Palacín, C., Præbel, K., Wangensteen, O.S., 2020. From metabarcoding to metaphylogeography: separating the wheat from the chaff. Ecol. Appl. 30, e02036. https://doi.org/10.1002/eap.2036

Vamos, E.E., Elbrecht, V., Leese, F., 2017. Short COI markers for freshwater macroinvertebrate metabarcoding. Metabarcoding Metagenomics 1, e14625. https://doi.org/10.3897/mbmg.1.14625

van der Heyde, M., Bunce, M., Wardell-Johnson, G., Fernandes, K., White, N.E., Nevill, P., 2020. Testing multiple substrates for terrestrial biodiversity monitoring using environmental DNA metabarcoding. Mol. Ecol. Resour. 20, 732-745. https://doi.org/10.1111/1755-0998.13148

Wickham, H., 2016. ggplot2: Elegant Graphics for Data Analysis. Springer-Verlag New York. Wickham, H., Francois, R., Henry, L., Müller, K., 2021. dplyr: A Grammar of Data Manipulation.

Yu, D.W., Ji, Y., Emerson, B.C., Wang, X., Ye, C., Yang, C., Ding, Z., 2012. Biodiversity soup: metabarcoding of arthropods for rapid biodiversity assessment and biomonitoring. Methods Ecol. Evol. 3, 613-623. https://doi.org/10.1111/j.2041210X.2012.00198.x 
bioRxiv preprint doi: https://doi.org/10.1101/2022.01.25.477667; this version posted January 26,2022 . The copyright holder for this preprint (which was not certified by peer review) is the author/funder, who has granted bioRxiv a license to display the preprint in perpetuity. It is made available under aCC-BY-ND 4.0 International license.

598 599 600 601 602 603 604 605 606 607 608 609 610 611 612 613
Zenker, M.M., Specht, A., Fonseca, V.G., 2020. Assessing insect biodiversity with automatic light traps in Brazil: Pearls and pitfalls of metabarcoding samples in preservative ethanol. Ecol. Evol. 10, 2352-2366. https://doi.org/10.1002/ece3.6042

Zizka, V.M., Leese, F., Peinert, B., Geiger Matthias F, 2019. DNA metabarcoding from sample fixative as a quick and voucher-preserving biodiversity assessment method. Genome 62, 122-136. https://doi.org/doi:10.1139/gen-2018-0048

Zizka, V.M.A., Elbrecht, V., Macher, J.-N., Leese, F., 2019. Assessing the influence of sample tagging and library preparation on DNA metabarcoding. Mol. Ecol. Resour. 19, 893-899. https://doi.org/10.1111/1755-0998.13018

Zizka, V.M.A., Geiger, M.F., Leese, F., 2020. DNA metabarcoding of stream invertebrates reveals spatio-temporal variation but consistent status class assessments in a natural and urban river. Ecol. Indic. 115, 106383.

https://doi.org/10.1016/j.ecolind.2020.106383 